\title{
In Ovo and In Silico Evaluation of the Anti-Angiogenic Potential of Syringin
}

This article was published in the following Dove Press journal:

Drug Design, Development and Therapy

\author{
Charlaine A Aventurado' \\ Junie B Billones $\mathbb{D}^{2}$ \\ Ross D Vasquez ${ }^{1,3,4}$ \\ Agnes L Castillo $\mathbb{D}^{1,3,4}$
}

'The Graduate School, University of Santo Tomas, Manila 1015, Philippines; ${ }^{2}$ Department of Physical Sciences and Mathematics, College of Arts and Sciences, University of the Philippines Manila, Manila, Philippines; ${ }^{3}$ Faculty of Pharmacy, University of Santo Tomas, Manila 1015, Philippines; ${ }^{4}$ Research Center for the Natural and Applied Sciences, University of Santo Tomas, Manila 1015, Philippines
Correspondence: Junie B Billones Department of Physical Sciences and Mathematics, College of Arts and Sciences, University of the Philippines Manila, Padre Faura, Manila I000, Philippines

Email jbbillones@up.edu.ph
Introduction: Cancer is considered as one of the deadliest human diseases today. Angiogenesis, the propagation of new blood vessels from pre-existing vasculature, is a critical step in the progression of cancer as it is essential in the growth and metastasis of tumors. Hence, suppression of angiogenesis is a promising approach in cancer therapy. Syringin, a phenylpropanoid glycoside with a molecular formula of $\mathrm{C}_{17} \mathrm{H}_{24} \mathrm{O}_{9}$, has been found to exhibit chemopreventive effects. However, its anti-angiogenic activity and the underlying mechanism of action are still unknown.

Methods: In this work, in ovo chorioallantoic membrane (CAM) assay has been conducted to evaluate the effect of syringin on neovascularization. Additionally, reverse molecular docking studies have been performed in order to identify the probable enzyme targets in the angiogenesis pathway.

Results: Treatment with syringin showed significant dose-dependent inhibition of blood vessel length and junctions in the CAM of duck eggs; the anti-angiogenic activity of syringin at $100 \mu \mathrm{M}$ and $200 \mu \mathrm{M}$ is comparable with $200 \mu \mathrm{M}$ of the positive control celecoxib. The results of reverse docking studies indicate that syringin binds the strongest to dihydrofolate reductase (DHFR) and, to some extent, with transforming growth factorbeta receptor type 1 (TGF- $\beta R 1)$, vascular endothelial growth factor receptor 2 (VEGFR2), and matrix metalloproteinase-2 (MMP-2). Furthermore, ADMET models revealed that syringin potentially possesses excellent pharmacokinetic and toxicity profiles.

Conclusion: This study demonstrates the potential of syringin as an anti-angiogenic agent and elicits further investigations to establish its application in cancer suppression.

Keywords: syringin, angiogenesis, cancer, molecular docking, reverse docking, dihydrofolate reductase, DHFR, TGF-ßR1, VEGFR2, MMP-2

\section{Introduction}

Cancer ranks as the second leading cause of death worldwide, accounting to 9.6 million mortalities in 2018. ${ }^{1}$ It is a complex disorder characterized by the abnormal proliferation and spread of malignant cells into surrounding tissues. ${ }^{2}$ Progression of this condition relies on its capacity to promote angiogenesis, ${ }^{3}$ which is the intricate process of initiating new blood vessels from pre-existing ones. ${ }^{4}$ The new capillary vessels are fundamental as they supply oxygen and sustenance that are indispensable in the growth and survival of malignancy. ${ }^{5}$ Moreover, these vessels are essential in the spread of cancer into other organs for they function as the transport channels of metastatic cells, implying that neovascularization is necessary in metastasis. The dependency of tumor progression on angiogenesis, ${ }^{3}$ together with its vital 
function in the pathological development and metamorphosis of neoplastic cells, makes this cascade an attractive target in cancer therapy. ${ }^{6}$

Impairment of signal transduction, due to genetic and epigenetic modifications, is a defining characteristic of cancer. ${ }^{7}$ Previous accounts have shed light on the significance of molecular interactions and signaling pathways in carcinogenesis. ${ }^{8}$ Neovascularization is affected by a number of molecular mediators such as growth factors, ${ }^{9}$ transcription factors, ${ }^{10}$ signaling pathways, ${ }^{11}$ extracellular matrix molecules, ${ }^{12}$ cytokines, $^{11}$ and many others. Due to the undesirable effects that manifest when chemotherapeutic agents attack normal cells, the use of targeted cancer therapy has become more appealing. ${ }^{13}$ Through the targeted approach, drug molecules specifically act at the pathways and proteins that serve critical roles in cancer and its microenvironment. ${ }^{14}$

Overexpression of numerous angiogenesis-related proteins is typical in many forms of cancer as they are crucial in the growth, spread, and progression of tumors. ${ }^{3,15}$ The complexity of the angiogenic system provides many targets for therapeutic intervention. ${ }^{16}$ With the current advances in molecular angiogenesis, novel molecular targets that are overexpressed in cancer have been identified. ${ }^{17}$ The vascular endothelial growth factor (VEGF/VEGFR2) pathway constitutes a series of signaling mechanisms that control the proliferation, migration, survival, as well as penetrability of vascular endothelial cells. ${ }^{18}$ The phosphorylation of VEGFR2 is recognized as a critical trigger in tumor angiogenesis. ${ }^{19}$ Transforming growth factor-beta (TGF- $\beta$ ) is vital for the stabilization of new vessels and is responsible for the production of extracellular matrix and the appropriate interaction between endothelial cells and mural cells. ${ }^{20}$ Matrix metalloproteinase-2 (MMP-2) is an extracellular remodeling enzyme that aids in the degradation of the basal membrane required for the migration and infiltration of proliferative endothelial cells in the course of angiogenesis. $^{21}$ Dihydrofolate reductase (DHFR) is an enzyme that plays a fundamental role in the synthesis of nucleic acid precursors, which are essential for cell proliferation and growth. ${ }^{22}$ Fibroblast growth factor receptors (FGFRs) regulate cell proliferation, differentiation, and angiogenesis. ${ }^{23}$ Tie2 is vital in vascular network formation, and its receptors act as regulators of angiogenesis and vessel maturation. ${ }^{24,25}$ Insulin-like growth factor-1 receptor (IGF$1 \mathrm{R})$ is commonly overexpressed in cancer. ${ }^{26}$ Its signaling initiated by ligand binding mediates many crucial cell responses including angiogenesis, invasion, and metastasis of neoplasia. ${ }^{27,28}$ The complex and multifactorial nature of tumor angiogenesis, especially in advanced tumors, necessitates the use of therapeutic compounds that act broadly against cancer-specific targets and pathways in order to reduce challenges associated with developing resistance. Therefore, broadly acting natural drugs with very low toxicity have promising roles in preventing tumor angiogenesis. ${ }^{16}$

The majority of the standard chemotherapeutic agents cause systemic toxicity which impairs several healthy organs/tissues. $^{29}$ The toxicities of these drugs on the processes of metabolism and excretion could continuously lead to serious injury to the kidneys, liver, and heart that could, later on, cause coagulopathy and peripheral neuronal toxicity. ${ }^{30}$ Thus, there is an urgent need for less toxic drugs that can intercept and cure cancer.

Syringin, also known as Eleutheroside B or in its formal name 4-[(1E)-3-Hydroxy-1-propen-1-yl]-2,6-dimethoxyphenyl D-glucopyranoside (Figure 1), is a phenylpropanoid glycoside present in plants such as Eleutherococcus senticosus, ${ }^{31}$ Syringa velutina, ${ }^{32}$ Tinospora cordifolia, ${ }^{33}$ and numerous others. This compound was known to possess cytotoxic, apoptotic, and antitumor functions in an array of human cancer cell lines. ${ }^{34-37}$ These studies suggest that syringin is a promising agent for cancer treatment. Nonetheless, the role of syringin in the inhibition of angiogenesis and its underlying mechanism remains unknown.

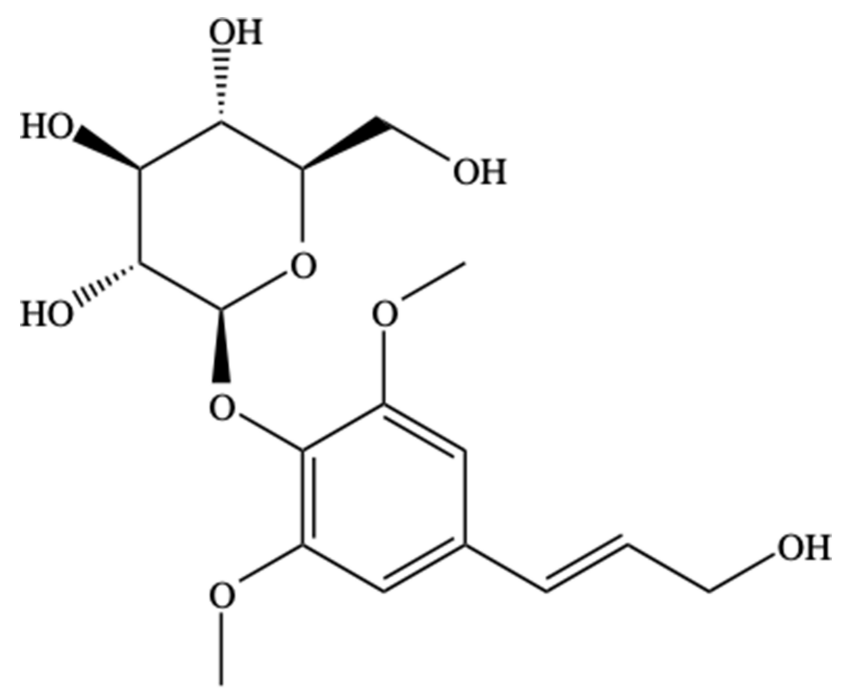

\section{Syringin}

$$
\mathrm{C}_{17} \mathrm{H}_{24} \mathrm{O}_{9} \quad \text { MW: } 372.4 \mathrm{~g} / \mathrm{mol}
$$

Figure I The structure of syringin. 
Drug discovery and development is a very costly and extensive procedure. ${ }^{38}$ Fortunately, computer-aided drug design (CADD) provides efficiency in minimizing the time, labor, and cost of drug research by the use of computational methods that can speed-up the entire process. ${ }^{39}$ These methods were instrumental in the discovery of new antineoplastic drugs that are used today. These include Gefitinib, ${ }^{40}$ Erlotinib ${ }^{41}$ Sorafenib ${ }^{42}$ Lapatinib, ${ }^{43}$ Abiraterone, ${ }^{44}$ and Crizotinib ${ }^{45}$ which are all approved medications that are initially discovered using computational methods. ${ }^{46}$

In this work, reverse molecular docking technique ${ }^{47,48}$ was conducted to understand the interaction of syringin with the molecular mediators involved in the multifaceted interplay in angiogenesis. The anti-angiogenic activity of syringin was evaluated through the chorioallantoic membrane (CAM) assay and the probable molecular targets of the title compound were identified using the reverse docking technique. Furthermore, in silico assessment of druglikeness and the compound's absorption, distribution, metabolism, excretion, and toxicity (ADMET) properties were also performed to predict the safety and oral druglikeness of syringin.

\section{Materials and Methods}

\section{Reagents and Materials}

Syringin ( $\geq 98 \%$ purity) was acquired from Chemfaces (Wuhan, China), and the standard Celecoxib ( $\geq 98 \%$ purity) was purchased from Sigma Aldrich (St. Louis, MO, USA). Phosphate buffer saline (PBS) was bought from Gibco (Waltham, MA, USA), while dimethylsulfoxide (DMSO) was obtained from J.T. Baker (Center Valley, PA, USA). All the other chemicals and reagents used in this study were of analytical reagent grade. Additionally, fertilized duck eggs were purchased from a hatchery in Baliuag, Bulacan, Philippines.

\section{Chick Chorioallantoic Membrane (CAM) Assay}

The effect of syringin on angiogenesis was evaluated through chorioallantoic membrane (CAM) assay as per the protocol of Thanekar et $\mathrm{al}^{49}$ with minor modifications on the method of analyzing vascular branching and choice of positive control. A total of six fertilized duck eggs were tested per group and were incubated using an Incubox automatic turning incubator maintained at $37^{\circ} \mathrm{C}$ with $85 \%$ relative humidity. Eggs between the $8^{\text {th }}$ and $10^{\text {th }}$ day of embryonic development (the peak of CAM neovascularization ${ }^{50}$ ) were utilized. Prior to the assay, the access portal was prepared by locating the embryo using a light source. Thereafter, the eggshells were marked and sanitized using $70 \%$ alcohol to create a $1-\mathrm{cm}^{2}$ window. The entire experiment was performed under sterile conditions to avoid contaminants. The incubator was disinfected and the tools were autoclaved before use.

Celecoxib $(200 \mu \mathrm{M})$ and syringin at various concentrations $(12.5 \mu \mathrm{M}, 25 \mu \mathrm{M}, 50 \mu \mathrm{M}, 100 \mu \mathrm{M}, 200 \mu \mathrm{M})$ were dissolved in dimethylsulfoxide (DMSO, $0.1 \% \mathrm{v} / \mathrm{v}$ ) with phosphate buffer saline (PBS). At day 8 of embryonic development, sterile filter paper discs $(10 \mathrm{~mm})$ loaded with $100 \mu \mathrm{L}$ of syringin, celecoxib, and $0.1 \%$ DMSO were aseptically placed over the blood vessel of a growing CAM through the access portal. Later on, adhesive tape was used to seal the eggshell, and the eggs were returned to the humidified incubator. After 48 hours, the eggs were reopened and the CAMs were observed and photographed. Photographs of the chorioallantoic membranes (CAMs) with the highest quality were chosen. The chosen visual field represents the region around the filter paper disc with the tested compounds. Photographs were taken at the same distance from the egg window to the lens of the camera. Through Angioquant version 1.33 (MATLAB Inc., Tampere, Finland), a software program for the analysis of blood vessels in images, the digital figures of the CAMs were inspected and parameters such as vessel length and its junctions were quantified. ${ }^{51}$ The antiangiogenic effect was then calculated using the following formula: ${ }^{52}$

Percentage inhibition $=$

$$
\frac{\text { score of control vessels }- \text { score of treated vessels }}{\text { score of control vessels }} \times 100
$$

\section{Molecular Modeling Computational Tools}

Protein-Ligand docking was accomplished with the use of Autodock Vina 1.1.23 in Python Prescription (PyRx) software, installed in an iMac desktop computer, equipped with $3.1 \mathrm{GHz}$ Intel Core i7 processor, 16GB RAM, and an NVIDIA GeForce $750 \mathrm{M}$ graphics card. Autodock Vina utilizes AMBER force field as the scoring parameter for molecular docking.

\section{Preparation of 3D Structure of Ligands and Protein Targets}

The crystal structures of dihydrofolate reductase (PDB ID: 1DRE), transforming growth factor-beta receptor type 1 
(PDB ID: 1VJY), vascular endothelial growth factor receptor 2 (PDB ID: 3EWH), matrix metalloproteinase-2 (PDB ID: $1 \mathrm{HOV})$, and other angiogenesis-related proteins were downloaded from Research Collaboratory for Structural Bioinformatics (RCSB) Protein Data Bank. Protein preparation was carried out using the UCSF Chimera 1.13 software and AutoDock tools of PyRx. Co-crystallized ligands, solvents, water molecules, and ions were removed, except for the ions that present essential roles in the ligand-target interaction. The location of the reference ligand in the protein structure was recorded and used to serve as the target site. Afterwards, the co-crystallized ligand was deleted to allow the interaction of test compounds with the binding site. The three-dimensional (3D) structure of ligands such as syringin (CID 5316860) (https://pubchem.ncbi.nlm.nih.gov/ compound/Syringin), as well as the other inhibitors evaluated, were retrieved from the PubChem compound database. The ligands were minimized in the OpenBabel tool using Universal Force Field (UFF) and then converted into AutoDock ligand format (PDBQT), which is suitable for docking in PyRx.

\section{Reverse Molecular Docking}

The potential targets of syringin in the cascade of angiogenesis were virtually examined by reverse docking approach to determine the probable targets of this ligand. Commonly known molecular targets involved in angiogenesis were chosen, and the binding modes, binding affinity, as well as the residue interaction of syringin on the active site of these proteins were determined. A grid-based docking method using a rigid protein receptor and flexible ligand was utilized in the experiment. ${ }^{53}$ The grid box was optimized to attain the best binding pose of the redocked native ligand which exhibits high similarity to the original co-crystallized ligand. The residues featured in the docking interaction, RMSD value, and generated pose were the basis in validating the docking parameters. The grid optimization protocol was executed using Autodock Vina, and the grid box encompasses the area containing the amino acid residues of the target binding site.

Listed in Table 1 are the important residues enclosed in the grid box as well as the grid box parameters of selected target proteins. The featured residues, RMSD value, and pose were the basis in evaluating the validity of the docking procedure.

The structures of the crystallized and redocked ligands were inspected using UCSF chimera 1.13 software (San Francisco, CA, USA). ${ }^{54}$ The two structures were superimposed and each pair of atoms was manually selected to calculate the root main square deviation (RMSD) values of the overlapped structures. The RMSD is a measure of the accuracy of the docking protocol used, ${ }^{55}$ an RMSD value of $<2 \AA$ being deemed successful. ${ }^{56,57}$ Moreover, the docking poses and ligand interactions were viewed using Biovia Discovery Studio Visualizer 2019 (Accelrys Inc., San Diego, CA, USA) to visually confirm if the essential residues and interactions observed in the crystal structure were maintained in the simulated structure.

\section{ADMET and Toxicity Predictions}

Aside from having therapeutic efficacy, it is also of prime importance that drug candidates possess excellent ADMET

Table I Residues and Grid Box Parameters of Selected Protein Targets

\begin{tabular}{|c|c|c|c|c|}
\hline $\begin{array}{l}\text { PDB } \\
\text { ID }\end{array}$ & Protein Target & Essential Residues Enclosed in the Grid Box & $\begin{array}{l}\text { Coordinates } \\
\text { of the } \\
\text { Center }\end{array}$ & $\begin{array}{l}\text { Dimension } \\
\text { of the Grid } \\
\text { Box }\end{array}$ \\
\hline 3EWH & $\begin{array}{l}\text { Vascular endothelial growth } \\
\text { factor receptor } 2 \text { (VEGFR2) }\end{array}$ & $\begin{array}{l}\text { Leu840, Val848, Ala866, Lys868, Glu885, Leu889, Ile892, Val898, } \\
\text { Thr916, Glu9I7, Cys919, LeuI019, His 1026, Leu 1035, Cys I045, } \\
\text { Asp1046, and Phel047 }\end{array}$ & $\begin{array}{l}x=17.001 \\
y=-5.309 \\
z=11.075\end{array}$ & $\begin{array}{l}x=18.962 \AA \\
y=19.437 \AA \\
z=23.602 \AA\end{array}$ \\
\hline IVJY & $\begin{array}{l}\text { Human transforming growth } \\
\text { factor-beta receptor type I } \\
\text { (TGF- } \beta \text { RI) }\end{array}$ & $\begin{array}{l}\text { Ile2II, Val219, Ala230, Lys232, Tyr249, Leu260, Phe262, Leu278, } \\
\text { Ser280, Tyr282, His283, Leu340, Ala350, Asp35I }\end{array}$ & $\begin{array}{l}x=15.853 \\
y=70.735 \\
z=4.389\end{array}$ & $\begin{array}{l}x=32.689 \AA \\
y=28.794 \AA \\
z=21.028 \AA\end{array}$ \\
\hline IHOV & $\begin{array}{l}\text { Matrix metalloproteinase-2 } \\
\text { (MMP-2) }\end{array}$ & $\begin{array}{l}\text { Leu42, Leu82, Leu83, Ala84, His85, Phel I5, Leul I6, ValII7, } \\
\text { His I20, GluI2I, His I30, LeuI37, IleI4I, ThrI43, Phel48, and } \\
\text { Zincl66 }\end{array}$ & $\begin{array}{l}x=6.559 \\
y=15.950 \\
z=19.597\end{array}$ & $\begin{array}{l}x=22.177 \AA \\
y=23.460 \AA \\
z=20.555 \AA\end{array}$ \\
\hline IDRE & $\begin{array}{l}\text { Dihydrofolate reductase } \\
\text { (DHFR) }\end{array}$ & $\begin{array}{l}\text { Ile5, Ala6, Ala7, Met20, Asp27, Lys32, Ser49, Ile50, Arg52, Arg57, } \\
\text { Ile94, Tyr } 100\end{array}$ & $\begin{array}{l}x=18.429 \\
y=18.855 \\
z=35.237\end{array}$ & $\begin{array}{l}x=23.897 \AA \\
y=23.201 \AA \\
z=20.492 \AA\end{array}$ \\
\hline
\end{tabular}


(Absorption, Distribution, Metabolism, Excretion, and Toxicity) properties. ${ }^{58}$ In this study, syringin was analyzed using the ADMET and TOPKAT (Toxicity Prediction by Komputer Assisted Technology) modules of Biovia Discovery Studio 2.5 (Accelrys Inc., San Diego, CA, USA). The ADMET descriptors protocol includes the determination of human intestinal absorption, aqueous solubility, blood-brain barrier (BBB) penetration, plasma protein binding, CYP2D6 inhibition, and hepatotoxicity. A quantitative structure-activity relationship (QSAR) model was utilized by this module to examine various attributes of the test compound. Meanwhile, carcinogenicity, mutagenicity, skin irritant activity, and others were evaluated using the TOPKAT module. The toxicity prediction protocol performs the assessment on a series of toxicity endpoints frequently employed in drug development. ${ }^{59}$ Furthermore, the conformance of syringin to Lipinski's rule of five ${ }^{60}$ was also assessed.

\section{Statistical Analysis}

Analysis of data was conducted using one-way analysis of variance (ANOVA), together with post hoc Tukey's comparison test in GraphPad Prism version 6.01 (San Diego, $\mathrm{CA}$, USA). Values were presented as mean $\pm \mathrm{SD}$, and findings were regarded as statistically significant when $P$ $<0.05$.

\section{Results and Discussion Anti-Angiogenic Activity}

Assessment of the anti-angiogenic responses of the drug was accomplished using the chorioallantoic membrane (CAM) assay. This assay is considered as the most widely used method in the evaluation of agents that affect blood vessel formation. ${ }^{61,62}$ DMSO at $0.1 \%$ concentration was used as the vehicle of the compounds and served as the negative control. Celecoxib was used as the positive control due to its established inhibitory activity in angiogenesis. ${ }^{63-68}$

The results of the chorioallantoic membrane (CAM) assay are summarized in Table 2. Celecoxib at $200 \mu \mathrm{M}$ inhibited the total number of junctions by $62.08 \pm 5.60 \%$ $(P<0.0001)$. Meanwhile, at $12.5 \mu \mathrm{M}, 25 \mu \mathrm{M}, 50 \mu \mathrm{M}, 100$ $\mu \mathrm{M}$, and $200 \mu \mathrm{M}$ concentrations, syringin was able to decrease the total number of junctions by $22.83 \pm 2.3 \%$, $29.81 \pm 3.4 \%, 39.61 \pm 3.3 \%, 63.19 \pm 2.34 \%$, and $66.98 \pm$ $3.62 \%$, respectively. When it comes to vessel length, celecoxib at $200 \mu \mathrm{M}$ was able to shorten it by $45.83 \pm 9.94 \%$
Table 2 Percentage Inhibition of Total Number of Junctions and Mean Length of Blood Vessels Treated with Syringin, Celecoxib, and $0.1 \%$ DMSO After 48 Hours of Treatment in CAM Assay

\begin{tabular}{|c|c|c|}
\hline Treatment Groups & $\begin{array}{l}\text { Percentage } \\
\text { Inhibition of Total } \\
\text { Number of } \\
\text { Junctions }\end{array}$ & $\begin{array}{l}\text { Percentage } \\
\text { Inhibition of } \\
\text { Mean Length of } \\
\text { Blood Vessels }\end{array}$ \\
\hline Syringin $200 \mu \mathrm{M}$ & $66.98 \pm 3.62 *$ & $55.14 \pm 8.94 *$ \\
\hline Syringin $100 \mu \mathrm{M}$ & $63.19 \pm 2.34 *$ & $44.15 \pm 8.20 *$ \\
\hline Syringin $50 \mu \mathrm{M}$ & $39.61 \pm 3.3^{*}$ & $25.42 \pm 6.74 *$ \\
\hline Syringin $25 \mu \mathrm{M}$ & $29.81 \pm 3.4^{*}$ & $14.64 \pm 3.15$ \\
\hline Syringin $12.5 \mu \mathrm{M}$ & $22.83 \pm 2.3^{*}$ & $10.38 \pm 4.16$ \\
\hline $\begin{array}{l}\text { Celecoxib } 200 \mu \mathrm{M} \\
\text { (Positive control) }\end{array}$ & $62.08 \pm 5.60 *$ & $45.83 \pm 9.94 *$ \\
\hline $\begin{array}{l}0.1 \% \text { DMSO } \\
\text { (Negative control) }\end{array}$ & $-0.01 \pm 1.92$ & $0 \pm 5.46$ \\
\hline
\end{tabular}

Notes: Values are summarized as mean \pm standard deviation, $(\mathrm{n}=6)$, * $\mathrm{P}$ value $<$ 0.0001 vs $0.1 \%$ DMSO (negative control group), $P$ value $<0.05$ vs $0.1 \%$ DMSO (negative control group).

$(P<0.0001)$, whereas syringin at $12.5 \mu \mathrm{M}, 25 \mu \mathrm{M}, 50$ $\mu \mathrm{M}, 100 \mu \mathrm{M}$, and $200 \mu \mathrm{M}$ reduced vessel length by 10.38 $\pm 4.16 \%, 14.64 \pm 3.15 \%, 25.42 \pm 6.74 \%, 44.15 \pm 8.20 \%$, and $55.14 \pm 8.94 \%$, respectively. It is also noteworthy that at $100 \mu \mathrm{M}$ and $200 \mu \mathrm{M}$, the activity of syringin is comparable with the percentage inhibition of $200 \mu \mathrm{M}$ celecoxib. These results demonstrate that syringin exhibits a significant dose-dependent decrease in the total number of junctions from $12.5 \mu \mathrm{M}$ to $200 \mu \mathrm{M}$, and mean vessel length from $50 \mu \mathrm{M}$ to $200 \mu \mathrm{M}$ in comparison with the negative control group $(P<0.0001)$. Representative images of treated membranes (Figure 2), and the percentage inhibition of the total number of junctions and mean length of blood vessels, as functions of concentration, are illustrated in Figure $3 \mathrm{~A}$ and $\mathrm{B}$, respectively.

\section{Reverse Molecular Docking Analysis}

It has been established that molecular docking is considered as a top screening approach in drug discovery and development. ${ }^{69}$ We demonstrated the utility of this technique in discovering new inhibitors of various druggable targets in M. tuberculosis. ${ }^{70-76}$ Reverse or inverse molecular docking helps in determining the probable protein targets of a ligand and shed some light on the possible mechanism of action of a drug. ${ }^{47,48}$ In this study, reverse docking was conducted to investigate the interaction between syringin and various angiogenesis-related proteins at the molecular level, particularly examining the hydrogen bonds, van der Waals and hydrophobic interactions, which 

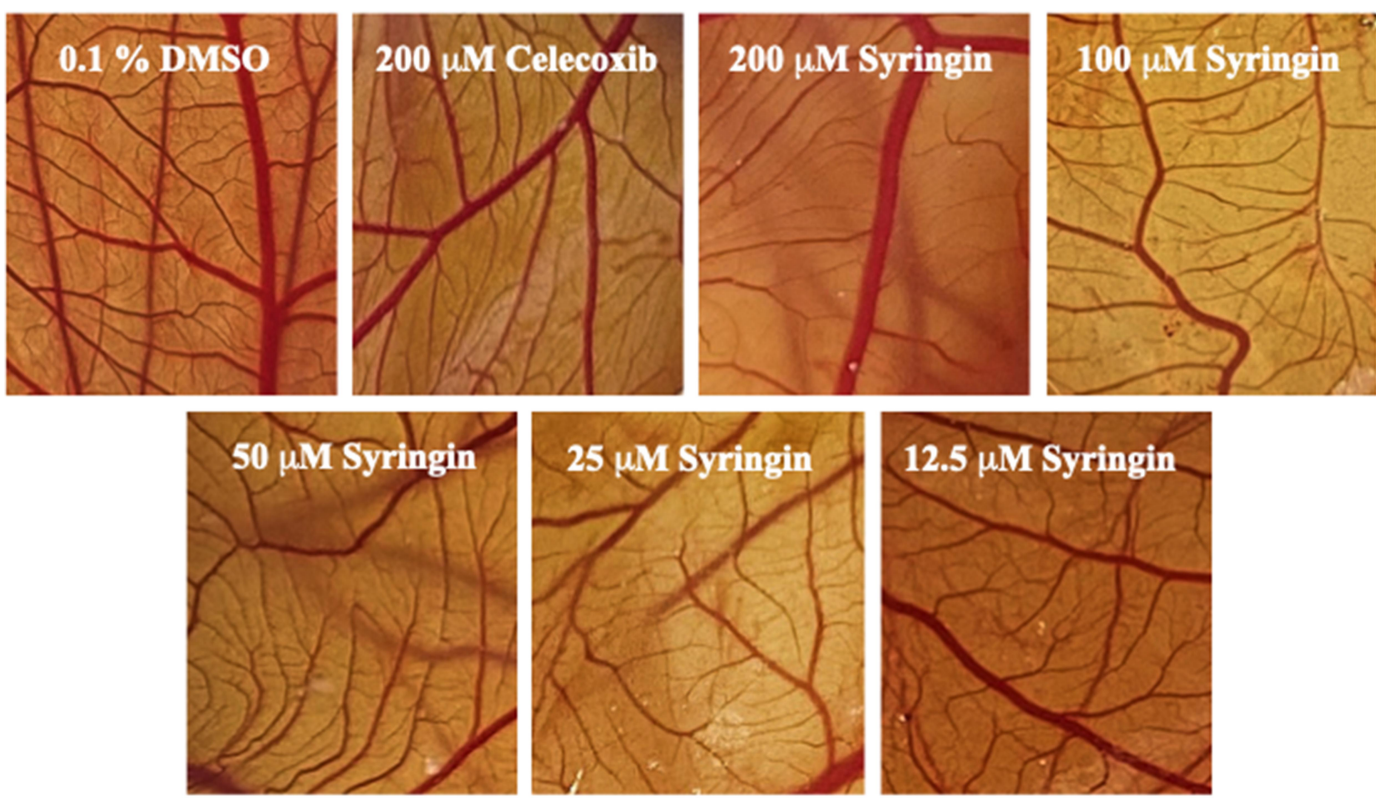

Figure 2 Representative images of chorioallantoic membranes (CAMs) upon exposure to various treatment groups.

A

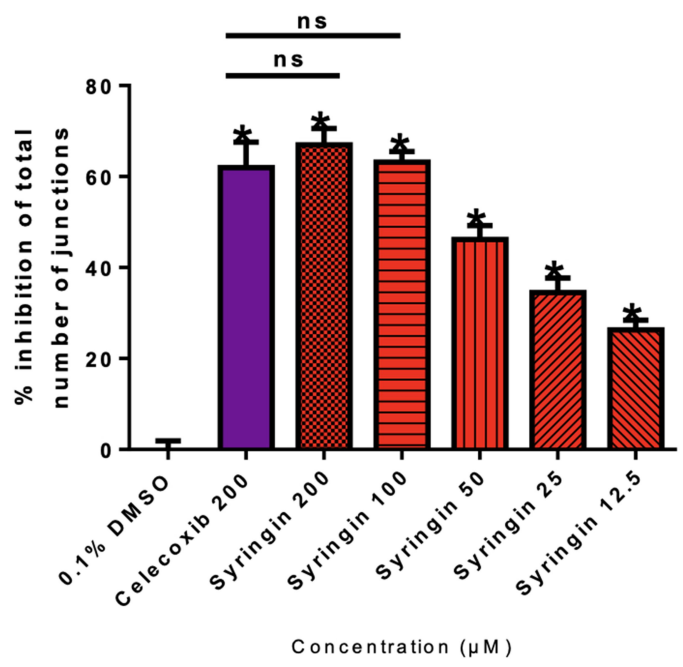

B

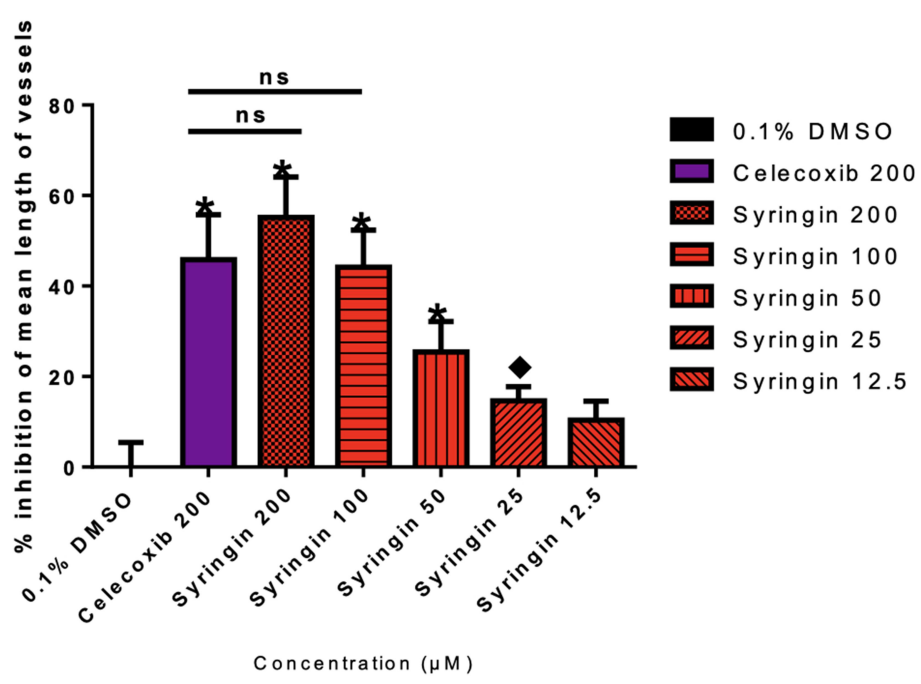

Figure 3 Chorioallantoic membranes (CAMs) treated with $0.1 \%$ DMSO, celecoxib, and syringin after 48 hours. (A) Graph demonstrating the percentage inhibition of the total number of junctions. (B) Graph denoting the percentage difference in mean length of blood vessels. Statistical analysis was calculated using one-way analysis of variance (ANOVA) followed by Tukey's post hoc test. There were statistically significant differences between the average total number of junctions of the negative control group ( $0.1 \%$ DMSO group) against all the concentrations of syringin and celecoxib. Meanwhile, syringin at 25 uM to 200 uM, along with $200 \mu M$ celecoxib, exhibited significant differences in the mean length of vessels parameter compared to the negative control group. Remarkably, syringin at $100 \mu \mathrm{M}$ and $200 \mu \mathrm{M}$ is statistically comparable with the $200 \mu \mathrm{M}$ positive control. Data are presented as mean \pm standard deviation, $(n=6), * P$ value $<0.000 \mathrm{I}$ vs $0.1 \%$ DMSO (negative control group), $P$ value $<0.05$ vs $0.1 \%$ DMSO (negative control group), ns - non-significant as compared with the positive control (celecoxib).

are the principal driving force in maintaining a stable ligand-protein complex. ${ }^{77}$

\section{Syringin-DHFR Interaction}

The folate pathway has been regarded as a crucial target in cancer chemotherapy. Dihydrofolate reductase (DHFR) is an enzyme that plays a fundamental role in the synthesis of nucleic acid precursors and is essential for cell proliferation and growth. ${ }^{22}$ It catalyzes the reduction of dihydrofolate to tetrahydrofolate through NADPH, a pocket situated deep within the enzyme. ${ }^{78}$ Meanwhile, methotrexate is an antifolate agent available in the market for various types of cancer. $^{79}$ However, aside from its poor pharmacokinetic property, its side effects include myelosuppression as well 
as impairment of the gastrointestinal tract, kidneys, and liver. ${ }^{80}$ Unfortunately, there is no available structure of DHFR from a human organism that is in complex with methotrexate, a standard antifolate drug. In contrast, ample literature shows that DHFR (eg, 1DRE) with methotrexate is common in the E. coli organization. A recent paper by Hobani et al also used the 1DRE structure to compare the effect of curcumin to methotrexate at the active site of DHFR protein. ${ }^{81}$ Thus, the interaction of syringin with DHFR using the 1DRE crystal structure was investigated. The RMSD value of the redocked ligand was $0.844 \AA$, which is within the accepted range. Syringin formed a complex with DHFR through six conventional hydrogen bonds with Ala6, Asn18, Ala19, Ser49, and Thr113. The other residues that had an interaction with the ligand include Ala7, Ile14, Met20, Phe31, and Tyr100. Syringin had a binding affinity of $-9.0 \mathrm{kcal} / \mathrm{mol}$, whereas the redocked methotrexate ligand had $-8.0 \mathrm{kcal} / \mathrm{mol}$. These results indicate that the binding of syringin with DHFR is stronger than the known ligand, methotrexate. Figure 4A shows the docked structures of syringin together with the antifolate drug methotrexate on the active site of 1DRE, Figure 4B shows the $3 \mathrm{D}$ image of syringin on the hydrogen bond surface of the protein, while Figure 4C and D demonstrate the $2 \mathrm{D}$ interaction diagrams of methotrexate and syringin with 1DRE, respectively.

\section{Syringin-TGF- $\beta$ R I Interaction}

The transforming growth factor- $\beta$ (TGF- $\beta$ ) pathway has been recognized as a mediator of numerous cellular responses affecting cancer. ${ }^{82}$ In the case of human transforming growth factor-beta receptor type 1 (PDB ID: 1VJY),
A

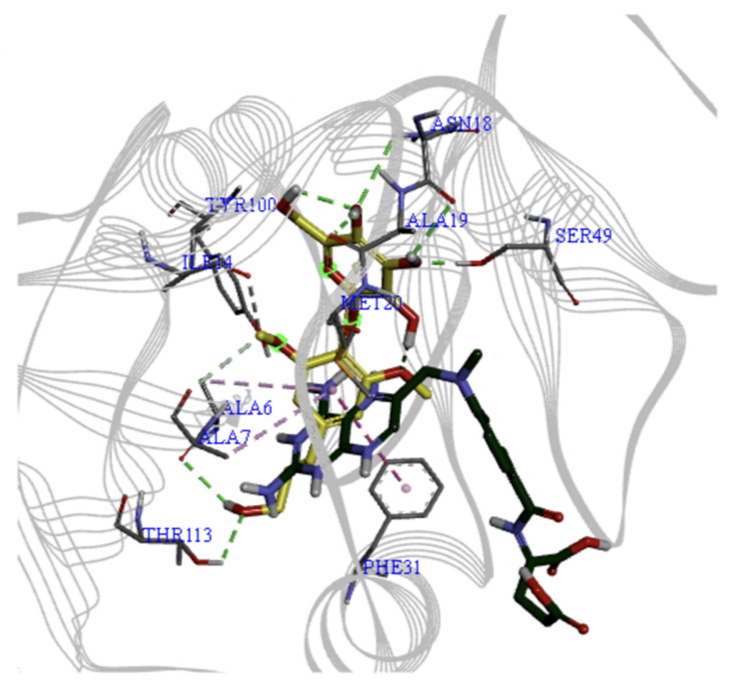

C

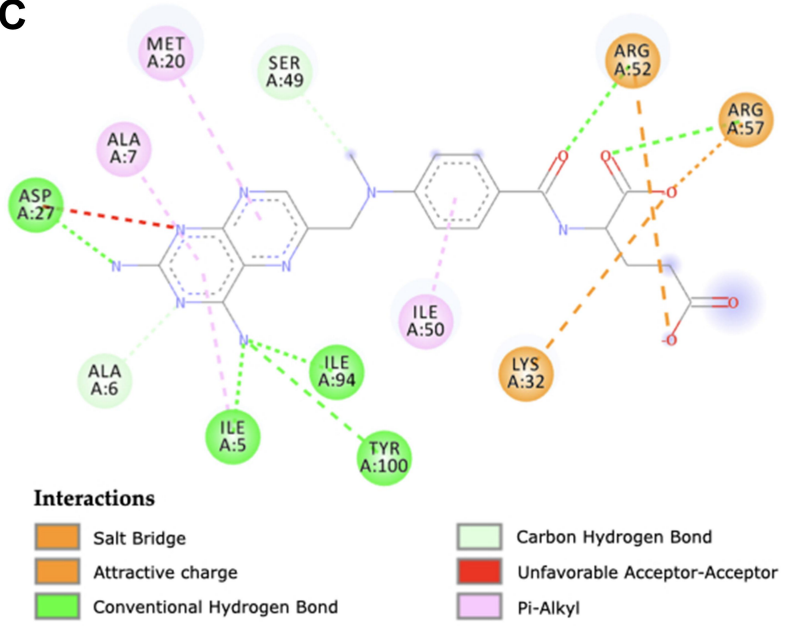

B

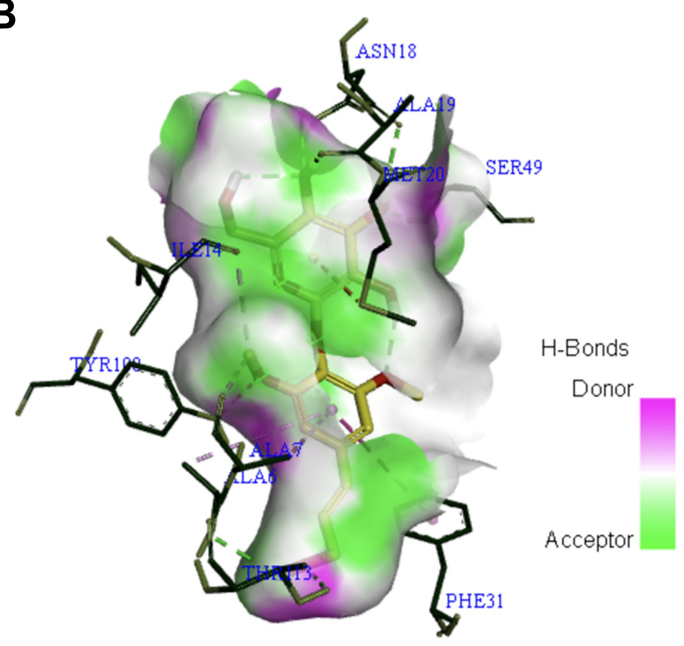

D

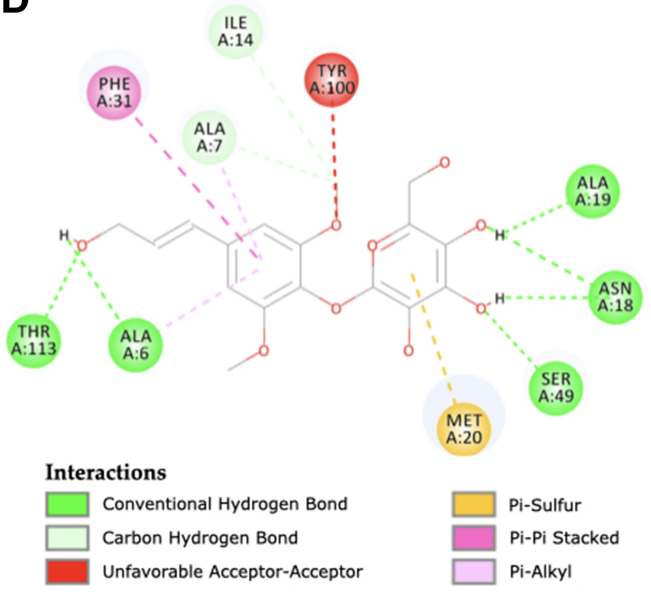

Figure 4 (A) Binding mode of syringin (yellow sticks) and methotrexate (green sticks) on the active site of dihydrofolate reductase (DHFR); (B) 3D docking snapshot with syringin on the surface of DHFR; (C) 2D interaction diagram of the native ligand (methotrexate) with DHFR; (D) 2D interaction diagram of syringin with DHFR. 
the key residues of this protein are Lys232, Leu260, Ser280, His283, and Asp351. ${ }^{83}$ As shown in Figure 5D, syringin had an interaction with all of the key residues, such as conventional hydrogen bond with Asp351 (Figure 5B), pi-cation with Lys232, pi-alkyl with Leu260, and van der Waals interaction with Ser280 and His283. Ser280 is considered a critical residue required for inhibitor selectivity, to which syringin had a van der Waals interaction. Compound 460 (Figure 5C), the redocked reference ligand, had a binding energy of $-10.2 \mathrm{kcal} / \mathrm{mol}$, while syringin had $-8.7 \mathrm{kcal} / \mathrm{mol}$. LY-580276 (Figure 5E), an established inhibitor, had a binding energy of $-9.6 \mathrm{kcal} / \mathrm{mol}$. The superimposed 3D interaction diagrams of syringin, compound 460, and LY580276 at the active site of 1VJY are presented in Figure 5A. Although considered comparable, the binding affinity of syringin with TGF- $\beta$ R1 protein target is slightly inferior compared to compound 460 and LY-580276.

\section{Syringin-VEGFR2 Interaction}

The VEGF/VEGFR2 pathway constitutes a series of signaling mechanism that controls the proliferation, migration, survival, as well as penetrability of vascular endothelial cells. ${ }^{18}$ For the VEGFR2 kinase domain (PDB ID: 3EWH), Glu885, Cys919, and Asp1046 are recognized as the key residues to which a compound will bind to for optimal interaction with the protein. Cys919 acts as a predominant residue responsible for the maintenance of inhibitor activity. ${ }^{84}$ As shown in Figure $6 \mathrm{~B}$ and $\mathrm{D}$, syringin had a conventional hydrogen bond with Cys 919 similar to the co-crystallized ligand, k11 (Figure 6C); while vandetanib (Figure 6E), an established inhibitor of VEGFR2, had an unfavorable interaction with the said residue. Furthermore, syringin formed van der Waals interaction with Glu885 and conventional hydrogen bond with Asp1046; vandetanib had a van der Waals interaction with both Glu885 and Asp1046; whereas k11 had an unfavorable interaction with Glu885 and Asp1046. The binding energy of syringin was $-7.5 \mathrm{kcal} / \mathrm{mol}$, while that of vandetanib and $\mathrm{k} 11$ were $-8.8 \mathrm{kcal} / \mathrm{mol}$ and $-12.2 \mathrm{kcal} / \mathrm{mol}$, respectively. Figure 6A depicts the binding mode of syringin along with vandetanib and the native ligand at the active site of $3 \mathrm{EWH}$. Despite the excellent binding affinity of $\mathrm{k} 11$, it has

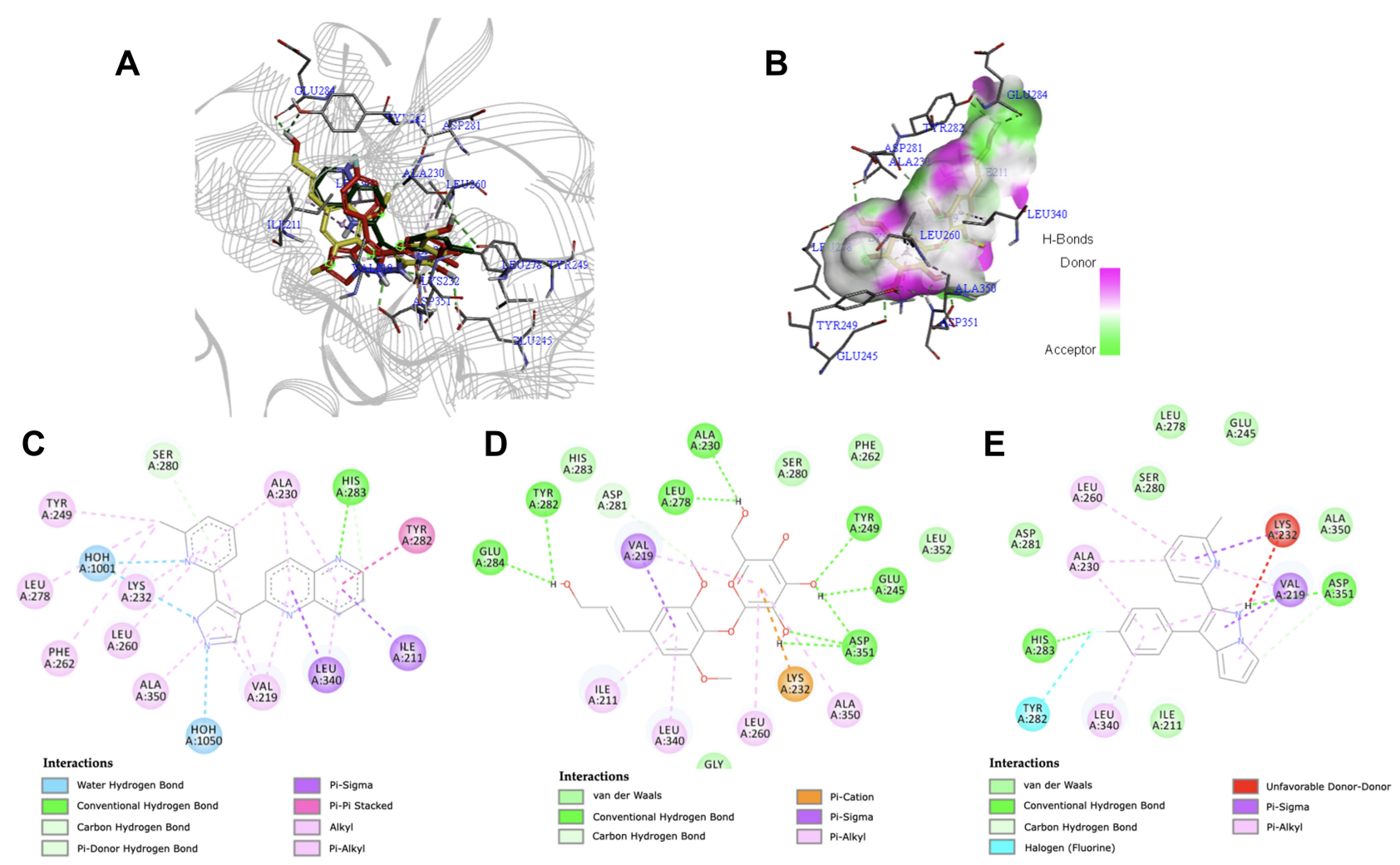

Figure 5 (A) Binding mode of syringin (yellow sticks), compound 460 (green sticks), and LY-580276 (red sticks) on the active site of transforming growth factor-beta receptor type I (TGF- $\beta R$ I); (B) 3D docking snapshot showing syringin on the surface of TGF- $\beta R$ I; (C) $2 \mathrm{D}$ interaction diagram of the native ligand (compound 460) with TGF- $\beta$ RI; (D) 2D interaction diagram of syringin with TGF- $\beta$ RI; (E) 2D interaction diagram of the established inhibitor (LY-580276) with TGF- $\beta$ RI. 


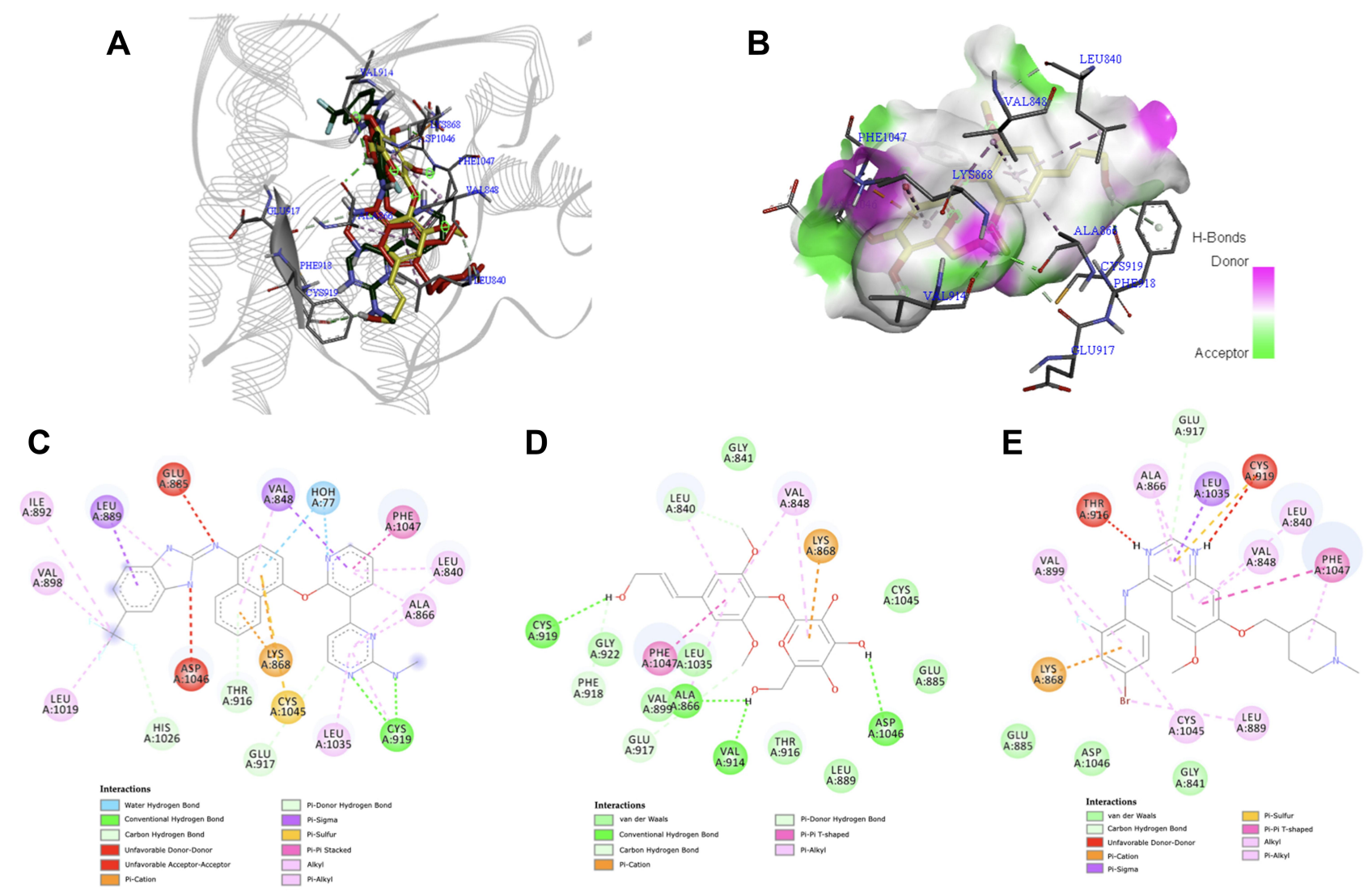

Figure 6 (A) Binding mode of syringin (yellow sticks), compound KII (green sticks), and vandetanib (red sticks) on the active site of vascular endothelial growth factor receptor 2 (VEGFR2); (B) 3D docking snapshot showing syringin on the surface of VEGFR2; (C) 2D interaction diagram of the native ligand (compound KII) with VEGFR2; (D) 2D interaction diagram of syringin with VEGFR2; (E) 2D interaction diagram of the established inhibitor (vandetanib) with VEGFR2.

a molecular weight of $527.511 \mathrm{~g} / \mathrm{mol},{ }^{85}$ which makes it quite undesirable as an oral drug candidate according to the Lipinski's rule. ${ }^{60}$

\section{Syringin-MMP-2 Interaction}

Matrix metalloproteinase-2 (MMP-2) is capable of degrading elastin, fibronectin, gelatin, as well as collagen types IV, $\mathrm{V}, \mathrm{VI}$, and $\mathrm{X},{ }^{86}$ which are all recognized as part of the principal components of the extracellular matrix. ${ }^{87}$ Numerous accounts supported the claim that a decrease in MMP-2 expression resulted in significant inhibition of angiogenesis in cancer. ${ }^{88-91}$ According to Agrawal et al, binding with zinc is usually regarded as a requirement for MMP inhibitors. ${ }^{92}$ Figure 7D shows that when syringin was docked against MMP-2 (PDB ID: 1HOV), it exhibited pication interaction with Zinc166. It also had a conventional hydrogen bond with Ala84 (Figure 7B and D), an extremely conserved residue in the target site of MMP. Moreover, His 120 and His 130 are some of the residues also present at the active site of the protein, and the compound of interest demonstrated pi-pi stacked and van der Waals interaction with those residues, respectively. Van der Waals interaction was also formed with Leu83, another backbone residue of 1HOV. ${ }^{93,94}$

The other interactions of syringin include conventional hydrogen bond with His85 and Ala139, carbon hydrogen bond with Glu121, and van der Waals interaction with Ile141 and Tyr142. The native ligand (i52) had a pi-cation interaction with Zinc166, conventional hydrogen bond with Ala84, pi-pi stacked interaction with His120, and carbon hydrogen bond with His130 (Figure 7C). Meanwhile, the known inhibitor marimastat (Figure 7E) had the following interactions with the crucial amino acid residues at the active site: conventional hydrogen bond with Ala84, carbon hydrogen bond with His120 and His130, and van der Waals interaction with Zinc166. Syringin, marimastat, and i52 were observed to bind into the active site of the protein cavity with a good fit (Figure 7A). Syringin exhibited a binding energy of $-6.9 \mathrm{kcal} / \mathrm{mol}$, while marimastat and i52 had $-6.6 \mathrm{kcal} / \mathrm{mol}$ and $-8.0 \mathrm{kcal} / \mathrm{mol}$, respectively. 


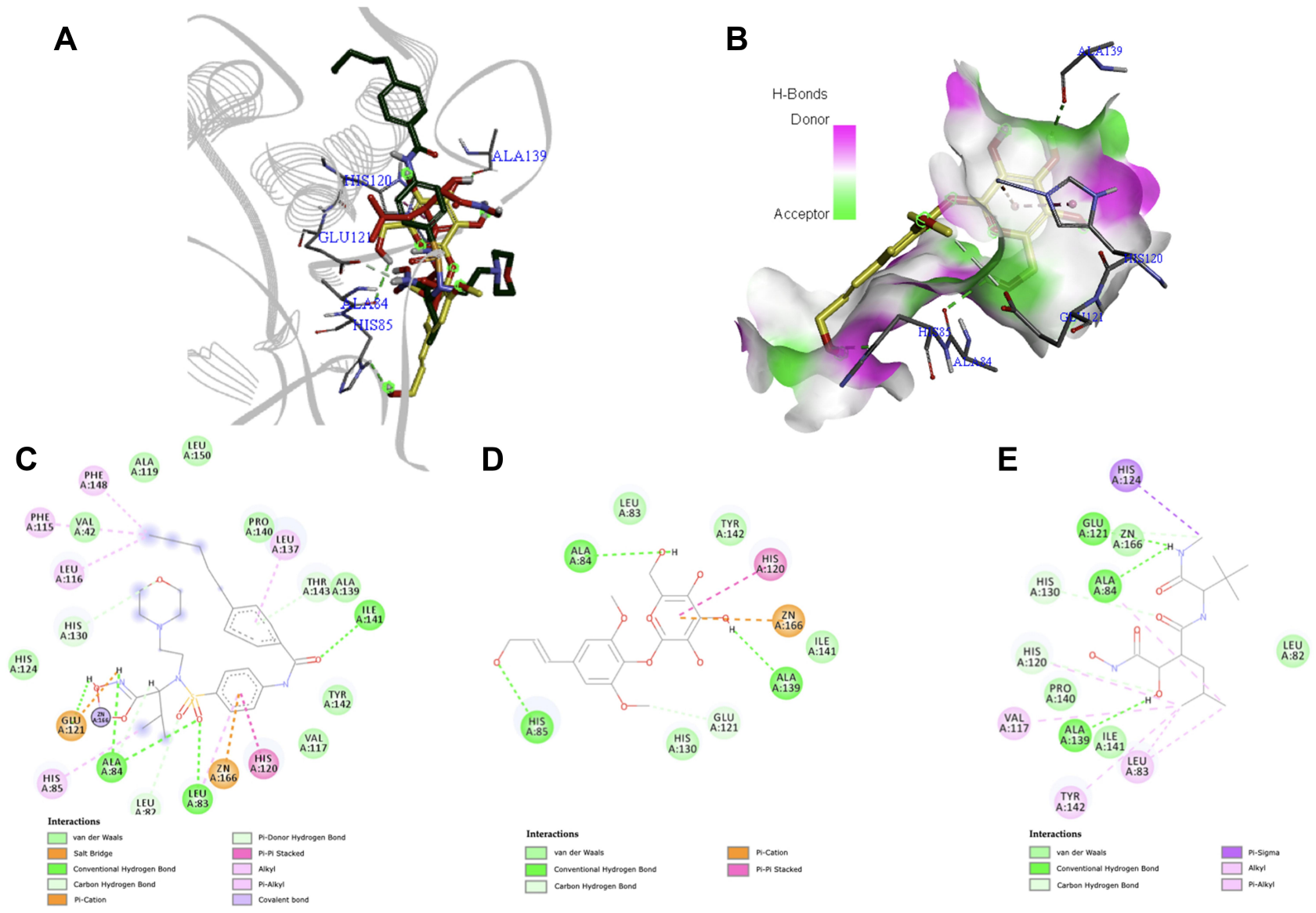

Figure 7 (A) Binding mode of syringin (yellow sticks), i52 (green sticks), and marimastat (red sticks) on the active site of matrix metalloproteinase-2 (MMP-2); (B) 3D docking snapshot showing syringin on the surface of MMP-2; (C) 2D interaction diagram of the native ligand (i52) with MMP-2; (D) 2D interaction diagram of syringin with MMP-2; (E) 2D interaction diagram of the established inhibitor (marimastat) with MMP-2.

Although i52 exhibited better binding affinity than syringin, i52 and marimastat both contain a hydroxamic acid moiety, which is linked to toxicity as well as mutagenicity, and has been documented to manifest unfavorable pharmacokinetics. $^{93,95}$ In this work, the ADMET and TOPKAT calculations (vide infra) indicate that syringin would most likely be nontoxic especially to the liver. Due to the unwanted effects exhibited by known inhibitors of MMP-2, ${ }^{96}$ new and effective MMP-2 suppressive agents with a safer profile must be explored.

As summarized in Table 3, syringin potentially binds to numerous angiogenesis-related proteins such as DHFR, TGF- $\beta$ R1, VEGFR2, and MMP-2. Although its binding affinity with these proteins may not be as high as some of the co-crystallized ligands and known inhibitors, syringin virtually binds with a multitude of proteins involved in neovascularization indicating the possible mechanism behind its anti-angiogenic activity.

\section{ADMET Profile}

The utmost reasons for the failure of the majority of drug candidates in clinical trials are inadequate ADME (absorption, distribution, metabolism, excretion) and high toxicity. ${ }^{97}$ Therefore, early assessment of the pharmacokinetics and toxicity profiles is vital in drug discovery. Syringin was reported to possess hepatoprotective ${ }^{98}$ and cardioprotective properties, ${ }^{99}$ which are desirable properties of an anti-cancer/anti-angiogenic agent. The majority of the standard chemotherapeutic medications cause systemic toxicity, which leads to serious injury to the liver and heart. ${ }^{30}$ Hence, prevention of these toxicities is vital for cancer survival. ${ }^{100}$ Thus, ADMET predictions were performed on syringin. Table 4 indicates that syringin would exhibit outstanding qualities as a drug candidate. Since the brain is not the target location in this study, it is desirable that the experimental compound does not penetrate the blood-brain barrier (BBB) to diminish any possible disturbances to the brain homeostasis. ${ }^{101}$ Delightfully, 
Table 3 Root-Mean-Square Deviation (RMSD) Values and Binding Energies for Syringin and Native Ligands in Complex with Various Angiogenesis Proteins

\begin{tabular}{|c|c|c|c|c|}
\hline PDB ID & Protein Target & RMSD & $\begin{array}{l}\text { Native Ligand } \\
\text { Binding Energy } \\
\text { (kcal/mol) }\end{array}$ & $\begin{array}{l}\text { Syringin Binding Energy } \\
\text { (kcal/mol) }\end{array}$ \\
\hline IDRE & Dihydrofolate reductase (DHFR) & 0.844 & -8.0 & -9.0 \\
\hline IVJY & Transforming growth factor-beta receptor type I (TGF- $\beta R$ I) & 0.551 & -10.2 & -8.7 \\
\hline 3EWH & Vascular endothelial growth factor receptor 2 (VEGFR2) & 0.706 & -12.2 & -7.5 \\
\hline IHOV & Matrix metalloproteinase 2 (MMP-2) & 1.135 & -8.0 & -6.9 \\
\hline 4QQ5 & Fibroblast growth factor receptor 4 (FGFR4) & 1.345 & -10.9 & -7.9 \\
\hline IT46 & c-Kit & 0.104 & -12 & -7.8 \\
\hline 3POZ & Epidermal growth factor receptor (EGFR) & 1.144 & -10.6 & -7.6 \\
\hline 4FA2 & P38 mitogen-activated protein kinase (MAPK) & 0.520 & -9.9 & -7.3 \\
\hline 2019 & Insulin-like growth factor-I receptor (IGF-IR) & 1.043 & -9.8 & -7.2 \\
\hline IUV5 & Glycogen Synthase Kinase 3B & 0.554 & -10 & -7.2 \\
\hline $3 \mathrm{HNG}$ & Vascular endothelial growth factor receptor I (VEGFRI) & 0.511 & -10.6 & -7.1 \\
\hline $2 \mathrm{P} 4 \mathrm{I}$ & Tie-2 & 1.353 & -12.0 & -7.1 \\
\hline $2 \times 9 F$ & EphB4 & 0.925 & -8.0 & -7.0 \\
\hline $5 E W 8$ & Fibroblast growth factor receptor I (FGFRI) & 1.136 & -8.3 & -6.9 \\
\hline $3 \mathrm{ClO}$ & Histone deacetylase 7 (HDAC7) & 0.991 & -7.8 & -6.8 \\
\hline $4 X U F$ & FMS-like tyrosine kinase-3 (FLT3) & 1.462 & -11.3 & -6.4 \\
\hline 4WUA & Serine-arginine protein kinase I (SRPKI) & 0.951 & -9.1 & -6.2 \\
\hline 3ERT & ER-alpha & 1.076 & -8.5 & -5.8 \\
\hline $3 \mathrm{C} 4 \mathrm{~F}$ & Fibroblast growth factor receptor (FGFR) & 0.572 & -9.8 & -5.5 \\
\hline IUW] & B-RAF & 1.018 & -12.3 & -8.1 \\
\hline 3PP0 & Human epidermal growth factor receptor 2 (HER2) & 0.679 & -11.2 & -8.1 \\
\hline 2DQM & Aminopeptidase $\mathrm{N}$ & 0.966 & -8.8 & -7.7 \\
\hline $5 J F R$ & Methionine amino peptidase 2 (MetAp2) & 0.325 & -8.6 & -7.3 \\
\hline
\end{tabular}

the ADMET results show that syringin has a very low permeation ability to the BBB. Furthermore, the title compound exhibits optimal solubility, a vital characteristic that affects the bioavailability of the drug. ${ }^{102}$ On the other hand, the absorption level of syringin was shown to be moderate, a characteristic that can be easily addressed by formulating the compound into a dosage form suitable for drugs with moderate absorption. Syringin was also

Table 4 ADMET Profile of Syringin

\begin{tabular}{|l|l|l|}
\hline ADMET Descriptors & Result & Description \\
\hline ADMET Blood-Brain Barrier & 4 & Very low \\
(BBB) Level & & \\
ADMET Absorption level & $\mathrm{I}$ & Moderate absorption \\
ADMET Solubility level & 4 & Optimal solubility \\
ADMET Hepatotoxicity & 0 & Nontoxic \\
ADMET Hepatotoxicity & 0.331 & Reliable prediction/ \\
Probability & & nontoxic \\
ADMET CYP2D6 & 0 & Non-inhibitor \\
ADMET Plasma Protein Binding & 0 & Not bound \\
(PPB) Level & & \\
\hline
\end{tabular}

predicted to be nontoxic to the liver, not bound to plasma proteins, and is not an inhibitor of CYP 2D6, suggesting that it will not cause drug-induced hepatotoxicity, is highly efficient in traversing cell membranes, therefore greater possibility to get to the target site, and less likely to affect the plasma concentration of other medications. These information indicate that there is a low probability that syringin will elicit drug-drug interactions at the pharmacokinetic level.

Furthermore, the TOPKAT data (Table 5) show that syringin is a non-carcinogenic, non-mutagenic, and non-skin irritant agent. Additionally, Table 6 indicates that the computed lethal dose $50\left(\mathrm{LD}_{50}\right)$ of syringin in rats is $10,000 \mathrm{mg} /$ $\mathrm{kg}$, which, according to Hodge and Sterner toxicity scale, is classified as practically non-toxic. ${ }^{103}$ Notably, the predicted maximum tolerated dose of the compound in rat models is $861 \mathrm{mg} / \mathrm{kg}$. These findings matched the in vivo study of Krishnan et al who conducted a toxicity investigation of syringin. Signs and symptoms of toxicity such as agitation, pulmonary distress, diarrhea, convulsions, and coma did not occur on Wistar rats administered with 10, 20, 30, 50, and 
Table 5 Toxicity Profile of Syringin

\begin{tabular}{|l|l|}
\hline TOPKAT Descriptors & Result \\
\hline Weight of Evidence (WOE) Probability of & Non-carcinogen \\
Carcinogenicity & \\
Aerobic Biodegradability & Biodegradable \\
AMES Mutagenicity & Non-Mutagen \\
AMES Single Benz & Non-mutagen \\
Skin irritation & Non-skin irritant \\
\hline
\end{tabular}

Table 6 Toxicity Prediction of Syringin in Rat Models

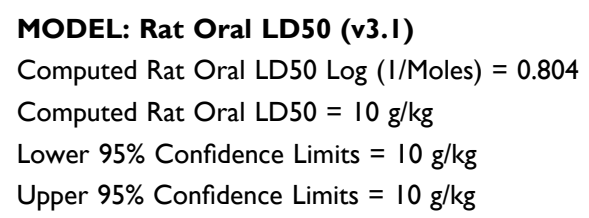

$100 \mathrm{mg} / \mathrm{kg}$ body weight of the test compound. ${ }^{104}$ These results imply that syringin is safe to use in in vivo analyses and possesses features worthy of further development into a clinically applicable drug.

The drug-like properties of syringin were also evaluated based on the Lipinski's rule of five. According to this rule, compounds with a partition coefficient $(\operatorname{LogP}) \leq 5$, molecular weight $\leq 500$, quantity of hydrogen bond acceptors $\leq 10$, quantity of hydrogen bond donors $\leq 5$, and topological polar surface area (TPSA) $<140 \AA^{2}$ are likely to exhibit good oral bioavailability, smooth membrane

Table 7 Drug-Like Properties of Syringin

\begin{tabular}{|c|c|c|}
\hline Parameter & Result & $\begin{array}{l}\text { Acceptable } \\
\text { Range }\end{array}$ \\
\hline $\begin{array}{l}\text { Octanol/Water Partition } \\
\text { Coefficient (LogP) }\end{array}$ & 2.083250 & $\leq 5$ \\
\hline Molecular Weight & $372.37 \mathrm{~g} / \mathrm{mol}$ & $\leq 500$ \\
\hline Hydrogen Bond Acceptor & 9 & $\leq 10$ \\
\hline Hydrogen Bond Donor & 5 & $\leq 5$ \\
\hline Topological Polar Surface Area & 138 & $<140 \AA^{2}$ \\
\hline
\end{tabular}

permeability as well as favorable gastrointestinal absorption. ${ }^{60}$ Table 7 reveals that syringin perfectly complies with the criteria of the Lipinski's rule, suggesting that this compound can be further developed as an oral drug for cancer. Furthermore, since it is predicted that the drug has a high maximum tolerated dose index, moderate to high doses may be considered to attain optimal inhibition of neovascularization.

\section{Conclusion}

The ever increasing incidence of cancer is making it a very serious health concern worldwide and attracts great interest in the field of medicinal research. For many years, plants, herbs, and other natural products have been utilized as therapeutic agents. Syringin, a phenylpropanoid compound present in diverse plant families, has been reported to elicit cytotoxicity and apoptotic activity. ${ }^{34-37}$ In this work, the chorioallantoic membrane (CAM) assay was conducted to assess the effect of the test compound on neovascularization. The results showed that the antiangiogenic activity of syringin at $100 \mu \mathrm{M}$ and $200 \mu \mathrm{M}$ is comparable with $200 \mu \mathrm{M}$ of celecoxib, the positive control. Furthermore, the reverse molecular docking study unveiled the probable angiogenesis targets that were inhibited by syringin as manifested in the CAM assay. Specifically, the activity of syringin was likely mediated by the inhibition of dihydrofolate reductase (DHFR), transforming growth factor-beta receptor type 1 (TGF$\beta R 1)$, vascular endothelial growth factor receptor 2 (VEGFR2), and matrix metalloproteinase-2 (MMP-2). These results will guide future enzyme-based assays that will further validate the anti-angiogenic action of syringin. In fact, further in vitro investigations are underway in our group. It is also noteworthy that syringin is a good candidate for drug development as it exhibited outstanding ADMET and drug-like properties. This is the first study to substantiate the angiogenesis inhibitory action of syringin and its probable mechanism of action, demonstrating that it may be a feasible multi-targeted agent for antiangiogenic cancer therapy.

\section{Acknowledgments}

This study was funded by the Institutional Grant for Invigorating Basic Research on Health Sciences Phase II research program of the Department of Science and Technology-National Research Council of the Philippines (Project No. Q-006). The authors are also thankful to The Graduate School and the Research Center for the Natural 
and Applied Sciences, University of Santo Tomas, Manila, Philippines, as well as to the staff of the Emerging Interdisciplinary Research (EIDR) laboratory (OVPAAEIDR 12-001-121102) of the University of the Philippines Manila for the training, assistance, and for allowing them to use the facilities.

\section{Disclosure}

The authors report grants from the National Research Council of the Philippines during the conduct of the study. The authors report no other potential conflicts of interest in this work.

\section{References}

1. Cancer. Available from: https://www.who.int/health-topics/cancer\# tab=tab_1. Accessed January 15, 2020.

2. What Is Cancer? Available from: https://training.seer.cancer.gov/ disease/cancer/. Accessed January 5, 2020.

3. Nishida N, Yano H, Nishida T, Kamura T, Kojiro M. Angiogenesis in Cancer. Vasc Health Risk Manag. 2006;2(3):213-219. doi:10.2147/vhrm.2006.2.3.213

4. Adair TH, Montani J-P. Angiogenesis. San Rafael, CA: Morgan \& Claypool Life Sciences; 2011.

5. Folkman J. Angiogenesis. Annu Rev Med. 2006;57:1-18. doi:10.1146/annurev.med.57.121304.131306

6. Tahergorabi Z, Khazaei M. A review on angiogenesis and its assays. Iran J Basic Med Sci. 2012;15(6):1110.

7. Sever R, Brugge JS. Signal transduction in cancer. Cold Spring Harb Perspect Med. 2015;5(4):a006098. doi:10.1101/cshperspect.a006098

8. Kessenbrock K, Plaks V, Werb Z. Matrix metalloproteinases: regulators of the tumor microenvironment. Cell. 2010;141(1):52-67. doi:10.1016/j.cell.2010.03.015

9. Ferrara N, Kerbel RS. Angiogenesis as a therapeutic target. Nature. 2005;438(7070):967-974.

10. Mafu TS, September A, Shamley D. The potential role of angiogenesis in the development of shoulder pain, shoulder dysfunction, and lymphedema after breast cancer treatment. Cancer Manag Res. 2018;10:81-90.

11. Ucuzian AA, Gassman AA, East AT, Greisler HP. Molecular mediators of angiogenesis. J Burn Care Res. 2010;31(1):158-175. doi:10.1097/BCR.0b013e3181c7ed82

12. Neve A, Cantatore FP, Maruotti N, Corrado A, Ribatti D. Extracellular matrix modulates angiogenesis in physiological and pathological conditions. Biomed Res Int. 2014;2014:1-10. doi: $10.1155 / 2014 / 756078$

13. Baudino T. Targeted cancer therapy: the next generation of cancer treatment. Curr Drug Discov Technol. 2015;12(1):3-20. doi:10.2174/ 1570163812666150602144310

14. Padma VV. An overview of targeted cancer therapy. BioMedicine. 2015;5:4.

15. Barron GA, Goua M, Wahle KW, Bermano G. Circulating levels of angiogenesis-related growth factors in breast cancer: A study to profile proteins responsible for tubule formation. Oncol Rep. 2017;38(3):1886-1894. doi:10.3892/or.2017.5803

16. Wang Z, Dabrosin C, Yin X, et al. Broad targeting of angiogenesis for cancer prevention and therapy. Semin Cancer Biol. 2015;35 (Suppl):S224-s243. doi:10.1016/j.semcancer.2015.01.001

17. Fallah A, Sadeghinia A, Kahroba H, et al. Therapeutic targeting of angiogenesis molecular pathways in angiogenesis-dependent diseases. Biomed Pharmacother. 2019;110:775-785. doi:10.1016/ j.biopha.2018.12.022
18. Ji L, Wu M, Li Z. Rutacecarpine inhibits angiogenesis by targeting the VEGFR2 and VEGFR2-Mediated Akt/MTOR/p70s6k signaling pathway. Molecules. 2018;23(8):2047. doi:10.3390/molecules23082047

19. Luan X, Gao Y-G, Guan -Y-Y, et al. Platycodin D inhibits tumor growth by antiangiogenic activity via blocking VEGFR2-mediated signaling pathway. Toxicol Appl Pharmacol. 2014;281(1):118-124. doi:10.1016/j.taap.2014.09.009

20. Rouwkema J, Khademhosseini A. Vascularization and angiogenesis in tissue engineering: beyond creating static networks. Trends Biotechnol. 2016;34(9):733-745. doi:10.1016/j.tibtech.2016.03.002

21. García-Vilas JA, Quesada AR, Medina MÁ. Hydroxytyrosol targets extracellular matrix remodeling by endothelial cells and inhibits both ex vivo and in vivo angiogenesis. Food Chem. 2017;221:1741-1746. doi:10.1016/j.foodchem.2016.10.111

22. Kalogris C, Garulli C, Pietrella L, et al. Sanguinarine suppresses basal-like breast cancer growth through dihydrofolate reductase inhibition. Biochem Pharmacol. 2014;90(3):226-234. doi:10.1016/ j.bcp.2014.05.014

23. Mohammadi M, Olsen SK, Ibrahimi OA. Structural basis for fibroblast growth factor receptor activation. Cytokine Growth Factor Rev. 2005;16(2):107-137. doi:10.1016/j.cytogfr.2005.01.008

24. Sato TN, Tozawa Y, Deutsch U, et al. Distinct roles of the receptor tyrosine kinases Tie-1 and Tie-2 in blood vessel formation. Nature. 1995;376(6535):70-74. doi:10.1038/376070a0

25. Teichert M, Milde L, Holm A, et al. Pericyte-expressed Tie2 controls angiogenesis and vessel maturation. Nat Commun. 2017;8:1. doi:10.1038/ncomms 16106

26. Werner H. Tumor suppressors govern insulin-like growth factor signaling pathways: implications in metabolism and cancer. Oncogene. 2011;31(22):2703-2714. doi:10.1038/onc.2011.447

27. Grant MB, Mames RN, Fitzgerald C, Ellis EA, Aboufriekha M, Guy J. Insulin-like growth factor I acts as an angiogenic agent in rabbit cornea and retina: comparative studies with basic fibroblast growth factor. Diabetologia. 1993;36(4):282-291.

28. Samani AA, Yakar S, Leroith D, Brodt P. The role of the igf system in cancer growth and metastasis: overview and recent insights. Endocr Rev. 2007;28(1):20-47.

29. Schirrmacher V. From chemotherapy to biological therapy: a review of novel concepts to reduce the side effects of systemic cancer treatment. Int J Oncol. 2019;54(2):407-419.

30. Maeda H, Khatami M. Analyses of repeated failures in cancer therapy for solid tumors: poor tumor-selective drug delivery, low therapeutic efficacy and unsustainable costs. Clin Transl Med. 2018;7(1):11. doi:10.1186/s40169-018-0185-6

31. Huang L, Zhao H, Huang B, Zheng C, Peng W, Qin L. Acanthopanax senticosus: review of botany, chemistry and pharmacology. Die Pharmazie Int J Pharm Sci. 2011;66(2):83-97.

32. Park HJ, Lee MS, Lee KT, Sohn IC, Han YN, Miyamoto KI. Studies on constituents with cytotoxic activity from the stem bark of Syringa velutina. Chem Pharm Bull (Tokyo). 1999;47 (7):1029-1031. doi:10.1248/cpb.47.1029

33. Herowati R, Widodo GP. Molecular Docking studies of chemical constituents of Tinospora cordifolia on glycogen phosphorylase. Procedia Chem. 2014;13:63-68. doi:10.1016/j.proche.2014.12.007

34. Lee C-H, Huang C-W, Chang P-C, et al. Reactive oxygen species mediate the chemopreventive effects of syringin in breast cancer cells. Phytomedicine. 2019;61:152844. doi:10.1016/j.phymed.2019.152844

35. Xia N. Syringin exhibits anticancer effects in HeLa human cervical cancer cells by inducing apoptosis, cell cycle arrest and inhibition of cell migration. Bangladesh J Pharmacol. 2016;11(4):838-843. doi:10.3329/bjp.v11i4.27755

36. Xu JP. Cancer Inhibitors from Chinese Natural Medicines. Taylor \& Francis Group: Boca Raton: CRC Press; 2016.

37. Yang X, Yuan J, Wan J. Cytotoxic phenolic glycosides from Boschniakia himalaica. Chem Nat Compounds. 2012;48 (4):555-558. doi:10.1007/s10600-012-0308-z 
38. Mohs RC, Greig NH. Drug discovery and development: role of basic biological research. Alzheimer's Dementia. 2017;3 (4):651-657.

39. Leelananda SP, Lindert S. Computational methods in drug discovery. Beilstein J Org Chem. 2016;12(1):2694-2718. doi:10. 3762/bjoc. 12.267

40. Muhsin M, Graham J, Kirkpatrick P. Gefitinib. Nat Rev Drug Discov. 2003;2(7):515-516. doi:10.1038/nrd1136

41. Grunwald V, Hidalgo M Development of the epidermal growth factor receptor inhibitor Tarceva (TM) (OSI-774). New Trends in Cancer for the 21st Century 2003, 235-246.

42. Wilhelm S, Carter C, Lynch M, Lowinger T, Dumas J, Smith RA. Discovery and development of sorafenib: a multikinase inhibitor for treating cancer. Nat Rev Drug Discov. 2006;5:835-844. doi:10.1038/ $\operatorname{nrd} 2130$

43. Wood ER, Truesdale AT, Mcdonald OB, et al. A unique structure for epidermal growth factor receptor bound to GW572016 (Lapatinib): relationships among protein conformation, inhibitor off-rate, and receptor activity in tumor cells. Cancer Res. 2004;2004 (64):6652-6659. doi:10.1158/0008-5472.CAN-04-1168

44. Jarman M, Barrie SE, Llera JM. The 16,17-double bond is needed for irreversible inhibition of human cytochrome P450 (17 alpha) by abiraterone (17-(3-pyridyl)androsta-5,16-dien-3 beta-ol) and related steroidal inhibitors. J Med Chem. 1998;41:5375-5381. doi:10. $1021 / \mathrm{jm} 981017 \mathrm{j}$

45. Butrynski JE, D'adamo DR, Hornick JL, Dal Cin P, Antonescu CR, Jhanwar SC. Crizotinib in ALK-rearranged inflammatory myofibroblastic tumor. N Engl J Med. 1727-1733;2010(363).

46. Cui W, Aouidate A, Wang S, Yu Q, Li Y, Yuan S. Discovering anti-cancer drugs via computational methods. Front Pharmacol. 2020;11.

47. Kharkar PS, Warrier S, Gaud RS. Reverse docking: a powerful tool for drug repositioning and drug rescue. Future Med Chem. 2014;6 (3):333-342.

48. Billones JB. Reverse docking study unravels the potential Mycobacterium tuberculosis enzyme targets of agelasine F. Oriental J Chem. 2016;32(2):851-858. doi:10.13005/ojc/320210

49. Thanekar D, Dhodi J, Gawali N, et al. Evaluation of antitumor and anti-angiogenic activity of bioactive compounds from Cinnamomum tamala: in vitro, in vivo and in silico approach. South Afr $j$ Botany. 2016;104:6-14. doi:10.1016/j.sajb.2015.09.014

50. Deryugina EI, Quigley JP. Chick embryo chorioallantoic membrane model systems to study and visualize human tumor cell metastasis. Histochem Cell Biol. 2008;130(6):1119-1130. doi:10.1007/s00418008-0536-2

51. Niemisto A, Dunmire V, Yli-Harja O, Zhang W, Shmulevich I. Robust quantification of in vitro angiogenesis through image analysis. IEEE Trans Med Imaging. 2005;24(4):549-553. doi:10.1109/TMI.2004.837339

52. Zaman K, Rahim F, Taha M, et al. Synthesis, thymidine phosphorylase, angiogenic inhibition and molecular docking study of isoquinoline derivatives. Bioorg Chem. 2019;89:102999. doi:10.1016/ j.bioorg.2019.102999

53. Trott O, Olson AJ. AutoDock Vina: improving the speed and accuracy of docking with a new scoring function, efficient optimization, and multithreading. J Comput Chem. 2010;31(2):455-461.

54. Pettersen EF, Goddard TD, Huang CC, et al. System for exploratory research and analysis. $J$ Comput Chem. 2004;25 (13):1605-1612. doi:10.1002/jcc.20084

55. Kufareva I, Abagyan R. Methods of protein structure comparison. Methods Mol Biol Homol Modeling. 2011;231-257.

56. Morris GM, Lim-Wilby M. Molecular Docking. Mol Modeling Proteins. 2008;443:365-382.

57. Saleh-E-In MM, Roy A, Al-Mansur MA, et al. Isolation and in silico prediction of potential drug-like compounds from anethum Sowa L. Root extracts targeted towards cancer therapy. Comput Biol Chem. 2019;78:242-259.
58. Guan L, Yang H, Cai Y, et al. ADMET-score-a comprehensive scoring function for evaluation of chemical drug-likeness. Medchemcomm. 2019;10(1):148-157.

59. Wang J, Peng W, Li X, et al. Towards to potential 2-cyanopyrimidines cathepsin- $\mathrm{K}$ inhibitors: an in silico design and screening research based on comprehensive application of quantitative structure-activity relationships, molecular docking and ADMET prediction. J Mol Struct. 2019;2019(1195):914-928. doi:10.1016/j. molstruc.2019.06.020

60. Lipinski CA, Lombardo F, Dominy BW, Feeney PJ. Experimental and computational approaches to estimate solubility and permeability in drug discovery and development settings. Adv Drug Deliv Rev. 2001;23(1-3):3-25. doi:10.1016/S0169-409X(96) 00423-1

61. Vargas A, Zeisser-Labouèbe M, Lange N, Gurny R, Delie F. The chick embryo and its chorioallantoic membrane (CAM) for the in vivo evaluation of drug delivery systems. Adv Drug Deliv Rev. 2007;59(11):1162-1176. doi:10.1016/j.addr.2007.04.019

62. Mousa SA, Yalcin M, Davis PJ. Models for assessing anti-angiogenesis agents: appraisal of current techniques. Anti-Angiogenesis Strategies Cancer Ther. 2017;21-38.

63. Gungor H, Ilhan N, Eroksuz H. The effectiveness of cyclooxygenase-2 inhibitors and evaluation of angiogenesis in the model of experimental colorectal cancer. Biomed Pharmacother. 2018;102:221-229. doi:10.1016/j.biopha.2018.03.066

64. Kang KB, Wang TT, Woon CT, et al. Enhancement of glioblastoma radioresponse by a selective COX-2 inhibitor celecoxib: inhibition of tumor angiogenesis with extensive tumor necrosis. Int $J$ Radiat Oncol Biol Phys. 2007;67(3):888-896.

65. Mandracchia D, Tripodo G, Trapani A, et al. Inulin based micelles loaded with curcumin or celecoxib with effective anti-angiogenic activity. Eur J Pharm Sci. 2016;93:141-146. doi:10.1016/j. ejps.2016.08.027

66. Raut CP, Nawrocki S, Lashinger LM, et al. Celecoxib inhibits angiogenesis by inducing endothelial cell apoptosis in human pancreatic tumor xenografts. Cancer Biol Ther. 2004;3(12):1217-1224. doi:10.4161/cbt.3.12.1221

67. Rosas C, Sinning M, Ferreira A, Fuenzalida M, Lemus D. Celecoxib decreases growth and angiogenesis and promotes apoptosis in a tumor cell line resistant to chemotherapy. Biol Res. 2014;47(1):27. doi:10.1186/0717-6287-47-27

68. Vaish V, Sanyal SN. Role of Sulindac and Celecoxib in the regulation of angiogenesis during the early neoplasm of colon: exploring PI3-K/PTEN/Akt pathway to the canonical Wnt/ $\beta$-catenin signaling. Biomed Pharmacother. 2012;66(5):354-367. doi:10.1016/j. biopha.2012.01.004

69. Roy S, Kumar A, Baig MH, Masařík M, Provazník I. Virtual screening, ADMET profiling, molecular docking and dynamics approaches to search for potent selective natural molecules based inhibitors against metallothionein-III to study Alzheimer's disease. Methods. 2015;83:105-110. doi:10.1016/j.ymeth.2015.04. 021

70. Billones JB, Carrillo MCO, Organo VG, et al. Toward antituberculosis drugs: in silico screening of synthetic compounds against Mycobacterium tuberculosis 1,d-transpeptidase 2. Drug Des Devel Ther. 2016;10:1147-1157. doi:10.2147/DDDT.S97043

71. Billones JB, Carrillo MCO, Organo VG, et al. In silico discovery and in vitro activity of inhibitors against Mycobacterium tuberculosis 7,8-diaminopelargonic acid synthase (MtbBioA). Drug Des Devel Ther. 2017;11:563-574. doi:10.2147/DDDT.S119930

72. Billones JB, Carrillo MCO, Organo VG, Macalino SJY, Emnacen IA, Sy JBA. Virtual screening against Mycobacterium tuberculosis lipoate protein ligase $\mathrm{B}(\mathrm{MtbLipB})$ and in silico ADMET evaluation of top hits. Oriental $J$ Chem. 2013;29 (4):1457-1468. doi:10.13005/ojc/290423 
73. Uy VCC, Billones JB. Towards antituberculosis drugs: virtual screening for potential inhibitors of pantothenate synthetase of Mycobacterium tuberculosis. Philippine Sci Letters. 2012;5 (2):122-130.

74. Yang CTM, Billones JB. Towards antituberculosis drugs: molecular docking of curcumin and its analogues to pantothenate synthetase. Philippine J Sci. 2012;141(2):187-196.

75. Billones JB, Valle AMF. Structure-based design of inhibitors against maltosyltransferase GlgE. Oriental J Chem. 2014;30 (3):1137-1145. doi:10.13005/ojc/300326

76. Sampaco III, Billones AB, B J. Virtual screening of natural products, molecular docking and dynamics simulations on M. tuberculosis S-adenosyl-L-homocysteine hydrolase. Oriental J Chem. 2015;31(4):1859-1865.

77. Weng $\mathrm{C}$, Fu Y, Jiang H, Zhuang S, Li H. Binding interaction between a queen pheromone component $\mathrm{HOB}$ and pheromone binding protein ASP1 of apis cerana. Int $J$ Biol Macromol. 2015;72:430-436. doi:10.1016/j.ijbiomac.2014.08.046

78. Singh A, Deshpande N, Pramanik N, Jhunjhunwala S, Rangarajan A, Atreya HS. Optimized peptide based inhibitors targeting the dihydrofolate reductase pathway in cancer. Sci Rep. 2018;8(1):1-8.

79. Hagner N, Joerger M. Cancer chemotherapy: targeting folic acid synthesis. Cancer Manag Res. 2010;2:293.

80. Avendaño C, Menéndez JC. Antimetabolites. In: Medicinal Chemistry of Anticancer Drugs. Eds. Avendaño C, Menéndez JC, Amsterdam: Elsevier; 2008:9-52.

81. Hobani Y, Jerah A, Bidwai A. A comparative molecular docking study of curcumin and methotrexate to dihydrofolate reductase. Bioinformation. 2017;13(3):63-66. doi:10.6026/97320630013063

82. Guerrero PA, Mccarty JH. TGF- $\beta$ activation and signaling in angiogenesis. Physiol Pathol Angiogenesis Signaling Mech Targeted Ther. 2017.

83. Gellibert F, Woolven J, Fouchet M-H, et al. Identification of 1,5-Naphthyridine derivatives as a novel series of potent and selective TGF- $\beta$ Type I receptor inhibitors. J Med Chem. 2004;47 (18):4494-4506. doi:10.1021/jm0400247

84. Zhang Y, Chen Y, Zhang D, Wang L, Lu T, Jiao Y. Discovery of novel potent VEGFR-2 inhibitors exerting significant antiproliferative activity against cancer cell lines. J Med Chem. 2018;61 (1):140-157. doi:10.1021/acs.jmedchem.7b01091

85. K11. 3-[(4,6-Dipyridin-4-yl-1,3,5-triazin-2-yl)amino]-4-methylN-[3-(trifluoromethyl)phenyl] benzamide. Available from: https:// pubchem.ncbi.nlm.nih.gov/compound/138857895. Accessed Jan $10,2020$.

86. Jabłońska-Trypuć A, Matejczyk M, Rosochacki S. Matrix Metalloproteinases (MMPs), the Main Extracellular Matrix (ECM) enzymes in collagen degradation, as a target for anticancer drugs. J Enzyme Inhib Med Chem. 2016;31(sup1):177-183.

87. Yue B. Biology of the extracellular matrix. J Glaucoma. 2014;23.

88. Berglin L, Sarman S, Ploeg IVD, et al. Reduced choroidal neovascular membrane formation in matrix metalloproteinase-2-deficient mice. Invest Ophthalmol Visual Sci. 2003;44(1):403. doi:10.1167/ iovs.02-0180

89. Itoh Y, Ito A, Iwata K, Tanzawa K, Mori Y, Nagase NH. Plasma Membrane-Bound Tissue Inhibitor of Metalloproteinases (TIMP)-2 Specifically Inhibits Matrix Metalloproteinase 2 (Gelatinase A) Activated on the Cell Surface. J Biol Chem. 1998;273 (38):24360-24367. doi:10.1074/jbc.273.38.24360
90. Ohno-Matsui K, Uetama T, Yoshida $\mathrm{T}$, et al. Reduced retinal angiogenesis in MMP-2-deficient mice. Invest Ophthalmol Visual Sci. 2003;44(12):5370. doi:10.1167/iovs.03-0249

91. Pfeifer A, Kessler T, Silletti S, Cheresh DA, Verma IM. Suppression of angiogenesis by lentiviral delivery of PEX, a noncatalytic fragment of matrix metalloproteinase 2. Proc Natl Acad Sci. 2000;97(22):12227-12232. doi:10.1073/pnas.220399597

92. Agrawal A, Romero-Perez D, Jacobsen JA, Villarreal FJ, Cohen SM. Zinc-binding groups modulate selective inhibition of MMPs. ChemMedChem. 2008;3(5):812-820. doi:10.1002/cmdc. 200700290

93. Ahmad A, Sayed A, Ginnebaugh KR, et al. Molecular docking and inhibition of matrix metalloproteinase- 2 by novel difluorinatedbenzylidene curcumin analog. Am J Transl Res. 2015;7(2):298.

94. Mukherjee A, Adhikari N, Jha T, Pentanoic Acid A. Derivative targeting Matrix Metalloproteinase-2 (MMP-2) induces apoptosis in a chronic myeloid leukemia cell line. Eur J Med Chem. 2017;141:37-50. doi:10.1016/j.ejmech.2017.09.052

95. Smith GF. Designing drugs to avoid toxicity. Prog Med Chem Progress Med Chem. 2011;50:1-47.

96. Fingleton B. MMPs as therapeutic targets—still a viable option? Semin Cell Dev Biol. 2008;19(1):61-68. doi:10.1016/j.semcdb. 2007.06 .006

97. Gombar VK, Silver IS, Zhao Z. Role of ADME characteristics in drug discovery and their in silico evaluation: in silico screening of chemicals for their metabolic stability. Curr Top Med Chem. 2003;3 (11):1205-1225. doi:10.2174/1568026033452014

98. Gong $\mathrm{X}$, Zhang L, Jiang $\mathrm{R}$, Wang $\mathrm{CD}$, Yin XR, Wan JY. Hepatoprotective effects of syringin on fulminant hepatic failure induced by D-galactosamine and lipopolysaccharide in mice. J Appl Toxicol. 2014;34(3):265-271. doi:10.1002/jat.2876

99. Li F, Zhang N, Wu Q, et al. Syringin prevents cardiac hypertrophy induced by pressure overload through the attenuation of autophagy. Int J Mol Med. 2016;39(1):199-207. doi:10.3892/ijm.2016.2824

100. Kalam K, Marwick TH. Role of cardioprotective therapy for prevention of cardiotoxicity with chemotherapy: a systematic review and meta-analysis. Eur J Cancer. 2013;49(13):2900-2909. doi:10.1016/j.ejca.2013.04.030

101. El-Gamal KM, El-Morsy AM, Saad AM, Eissa IH, Alswah M. Synthesis, docking, QSAR, ADMET and antimicrobial evaluation of new quinoline-3-carbonitrile derivatives as potential DNA-gyrase inhibitors. J Mol Struct. 2018;1166:15-33. doi:10. 1016/j.molstruc.2018.04.010

102. Chung TD, Terry DB, Smith LH. In vitro and in vivo assessment of ADME and PK properties during lead selection and lead optimization-guidelines, benchmarks and rules of thumb. In: Assay Guidance Manual. Eds. Markossian S, Sittampalam GS, Grossman A, et al. Bethesda (MD): Eli Lilly \& Company and the National Center for Advancing Translational Sciences; 2015.

103. Hodge, HC, Sterner, JH. Tabulation of Toxicity Classes. American Industrial Hygiene Association Quarterly. 1949;10(4):93-96. doi:10.1080/00968204909344159

104. Krishnan SS, Subramanian IP, Subramanian SP. Isolation, characterization of syringin, phenylpropanoid glycoside from Musa paradisiaca tepal extract and evaluation of its antidiabetic effect in streptozotocin-induced diabetic rats. Biomed Prev Nutri. 2014;4 (2):105-111. doi:10.1016/j.bionut.2013.12.009 


\section{Publish your work in this journal}

Drug Design, Development and Therapy is an international, peerreviewed open-access journal that spans the spectrum of drug design and development through to clinical applications. Clinical outcomes, patient safety, and programs for the development and effective, safe, and sustained use of medicines are a feature of the journal, which has also been accepted for indexing on PubMed Central. The manuscript management system is completely online and includes a very quick and fair peer-review system, which is all easy to use. Visit http://www. dovepress.com/testimonials.php to read real quotes from published authors. 